\title{
Quiste bronquial congénito (Presentación de 4 casos)
}

\author{
DRS.: E. CORTES *, L. BOZA *, D. MIRKIN **, R, BURDACH*, M. MENA ***,
}

El concepto de tumoración mediastínica y pulmonar abarca en la infancia una escala de procesos inespecíficos y específicos, hiperplásicos benignos y malignos, quísticos o sólidos, inflamatorios o no del área mediastínica y pulmonar.

Dependiendo de su localización va a ser la precocidad de la sintomatología clínica (1).

Si hacemos una división del mediastino en anterior, posterior, superior, medio e inferior, los quistes broncógenos (Q.B.) se encuentran ubicados en la región superior o media hacia posterior, exactamente por delante de la columna vertebral, pero no tan detrás como los tumores neurógenos (2). Además de esta ubicación pueden hacerlo en la pared del esófago, pericardio y parénquima pulmonar (3). Las series extranjeras sugieren que los quistes broncógenos son más frecuentes que los realmente registrados y estarían situados de acuerdo a su frecuencia entre tercero y quinto lugar dentro de los tumores mediastínicos (4).

MATERIAL. Se presentan 4 casos de quistes broncógenos, uno de ellos asociado a una variedad de enfisema lobar congénito.

Caso clinico 1: J.I.M. Obs, 187278. Fecha de Nac.: 14-V-67.

Escolar de 6 años de edad, sin antecedentes personales ni familiares de importancia.

Ingresa al Servicio de Urgencia a los 5 meses de edad, muy grave, clínicamente en insuficiencia pulmonar, afebril, Ex. Físico torácico revela abom-

\footnotetext{
* Departamento de Enfermedades Respiratorias. Hospital M. Arriarán. Santiago - Chile.

Servicio de Anatomía Patológica. Hospital Roberto del Río. Santiago - Chile.

*** Radiologia. Hospital M. Arriarán. Santiago - Chile.
}

bamiento del H.I., hipersonoridad, abolición del murmullo vesicular, soplo anfórico, mediastino desviado a derecha.

Radiológicamente,' se aprecia gran imagen aérea que compromete el pulmón izquierdo con desplazamiento de mediastino y en lateral la imagen se proyecta hacia el plano anterior.

Toracotomía descompresora da salida a abundante cantidad de aire y líquido achocolatado, cultivo del mismo fue negativo. Evolución tórpida, con agravamiento al retiro de la sonda de drenaje, al formarse y comprobarse radiológicamente reproducción de la imagen aérea.

Hemograma. Hto 30\%-Hb 9,1 gr\%. VSH $25 \mathrm{~mm}$. Microcitosis, hipocromía. Leucocitosis 18800. Sin desv. izq.

Al comprobarse que el cuadro no cede se interviene quirúrgicamente a los 37 días de hospitalización interpretándose en el acto operatorio como neumatocele del segmento dorsal del LII, El LSI, es normal y se expande perfectamente. Histopatológicamente: Quiste bronquial congénito.

Excelentes condiciones hasta junio 1973 en que bruscamente presenta fiebre, tos $\mathrm{y}$ hemoptisis de

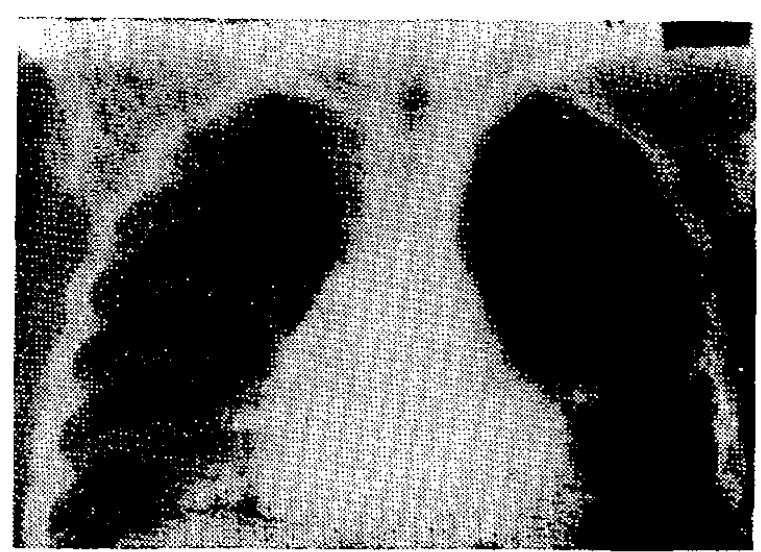

Flgura N: 1 
10 días de evolución por lo que se hospitaliza, Radiografías revelan imagen aérea grande de contornos nítidos en relación a LSI (Fig. 1). Broncográficamente se demuestra desplazamiento hacia abajo de las ramas bronquiales del segmento anterior del LSI y de las ramas de la língula por imagen bulosa que no se llenó de medio de contraste.

Se interviene en noviembre de 1973, resecándose quiste del LSI en su segmento apical. Histológicamente revela displasia pulmonar compatible con quiste bronquial congénito. Controlado en enero de 1974, revela clínica y radiológicamente pulmones normales.

Caso clínico 2: S.V.H. Obs. 266397. Fecha de Nac.: 23-X-64.

Escolar de 9 años, sin antecedentes personales ni familiares de importancia; procedente de la ciudad de Punta Arenas.

Desde los 7 meses de edad presenta cuadros bronquiales hipersecretores casi permanentes, no efectuándose estudios al respecto.

A los 9 años se efectúan exámenes radiológicos encontrándose imagen sospechosa de quiste bronquial, por lo que es referida a Santiago.

Al ingreso destaca estridor sibilante persistente, con tos frecuente de tipo catarral sin expectoración de predominio nocturno.

Radiológicamente, en placa frontal revela campos pulmonares libres, en lateral, se aprecia imagen densa ovoidea a nivel del plano medio, por delante de la bifurcación traqueal. Se practica broncografía bilateral en que se aprecia ángulo carinal aumentado de tamaño y con bronquios fuentes rodeando a una masa que se llena de medio de contraste (Fig. 2). Conclusión radiológica: Quiste broncógeno comunicado a vía érea.

Exámenes habituales de laboratorio fueron nor. males, como así un estudio laringoscópico. Se interviene quirúrgicamente en noviembre de 1973, y se comprueba quiste subcarinal. Histopatológicamente se concluye que se trata de Quiste bronquial congénito. Evolución satisfactoria.

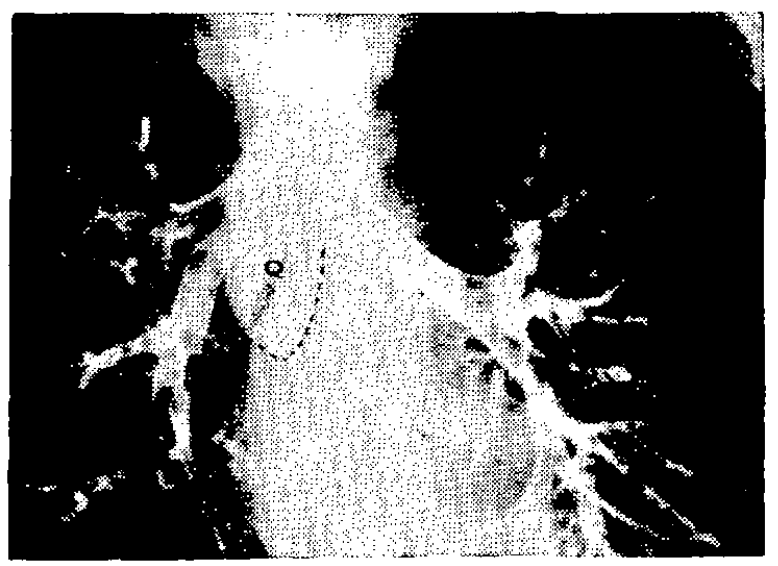

Figura № 2

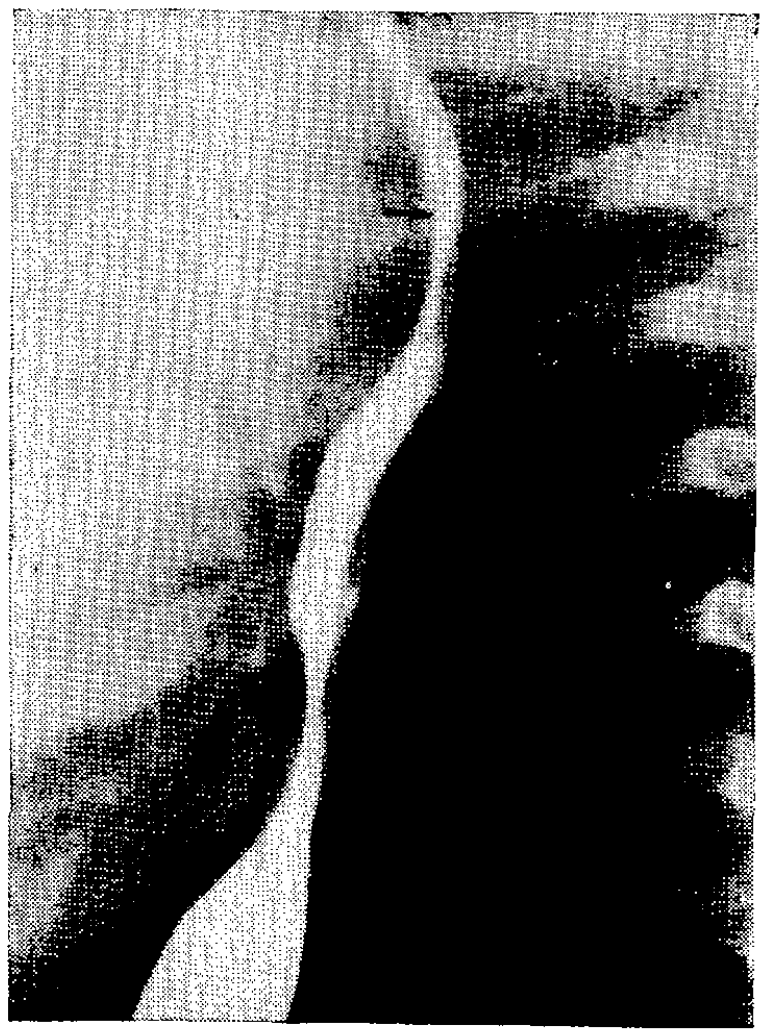

Figura No 3

Caso clinico 3: C.J.G. Obs, 259013. Fecha de Nac.: 4-VIII-72.

Lactante de 1 año 10 meses de edad, presenta desde los 8 días de vida síndrome bronquial obstructivo de carácter permanente.

Al cuarto mes existe dificultad en la alimentación lo que es apreciado por la madre, con mejoría evidente a la hiperextensión del cuello y posición erecta.

Fuera de estos antecedentes no existen otros de importancia.

A los 8 meses de edad es referido para ser estudiado, hospitalizándose.

Al ingreso se comprueba niño con polipnea de sesenta por minuto, tiraje y retracción costal de mediana intensidad. Intenso estridor respiratorio, audible en los dos momentos del ciclo. (Inspiración, espiración).

Radiografía frontal demuestra sombras difusas de condensación en tercio inferior izquierdo, hiperinsuflación del LSI con desviación de mediastino a derecha. En plano lateral se aprecia a nivel del mediastino superior imagen densa ovoidea que desplaza tráquea hacia adelante. Por la dificultad en la alimentación se efectúa esofagograma, encontrándose nuevamente la imagen ovoidea y densa que rechaza esófago hacia atrás y tráquea hacia adelante (Fig. 3). 
No se efectuó broncografía. Laringoscopía demuestra laringitis crónica inespecífica. Exámenes habituales de laboratorio sin particularidades. Se interviene quirúrgicamente con el diagnóstico de quiste bronquial, (la hiperinsuflación del LSI se relaciona al quiste).

Intervenido en abril de 1973, se comprueba el quiste bronquial, que se encuentra implantado en la cara membranosa de la tráquea, provocándole efracción de la zona posterior que hubo que suturar.

Histopatológicamente: Quiste bronquial congénito.

Mayo de 1973, se da de alta en buenas condiciones generales, persistiendo polipnea. Radiografía de aquella fecha demuestra disminución de la insuflación del LSI, con moderado desplazamiento a derecha.

A los 10 meses de su operación, consulta por bronquitis hipersecretora de carácter permanente, tres meses después es hospitalizada.

Radiografías, demuestran sombras difusas, tenues del tercio inferior izqdo, hiperclaridad de los dos tercios superiores del mismo pulmón; desplacamiento de mediastino a derecha.

Ante la sospecha de que se tratara de un enfisema lobar congénito, se practica broncografía bilateral encontrándose a izqda., desplazamiento hacia abajo de las ramas bronquiales, que se observan conglomeradas y de calibre normal, hiperclaridad de la mitad superior del H.izqdo., árbol bronquial derecho normal. Como Ex. complementario se efectuó tránsito esófago-gastro-duodenal que reveló escaso reflujo, sin ectopia gástrica.

Exámenes generales n/e. Gases arteriales, hiperventilación crónica.

Se envía a Cirugía en junio de 1974, con diagnóstico de enfisema lobar congénito, lo que se comprueba operatoriamente.

Histopatológicamente se encuentra dilatación marcada de alvéolos, atrios, bronquiolos y bronquios en áreas apicales del LSI, sin componente inflamatorio significativo ni signos evidentes de obstrucción intrínseca correspondiendo al denominado Enfisema Regional Infantil, variedad clínico. patológica del enfisema lobar congénito (5).

Caso clinico 4: P.C.J. Obs. 280296. Fecha de Nac.: 12-II-74.

Lactante sin antecedentes personales o familiares de importancia. Su primera consulta data a los 8 meses de edad por presentar neumopatía aguda de predominio derecho, con síndrome bronquial obstructivo. Radiológicamente se caracterizó por sombra densa de límite externo preciso basal derecho, hiperclaridad bilateral, pequeña hernia mediastínica anterior izqda. No se tienen otros antecedentes por ser atendido en otro servicio.

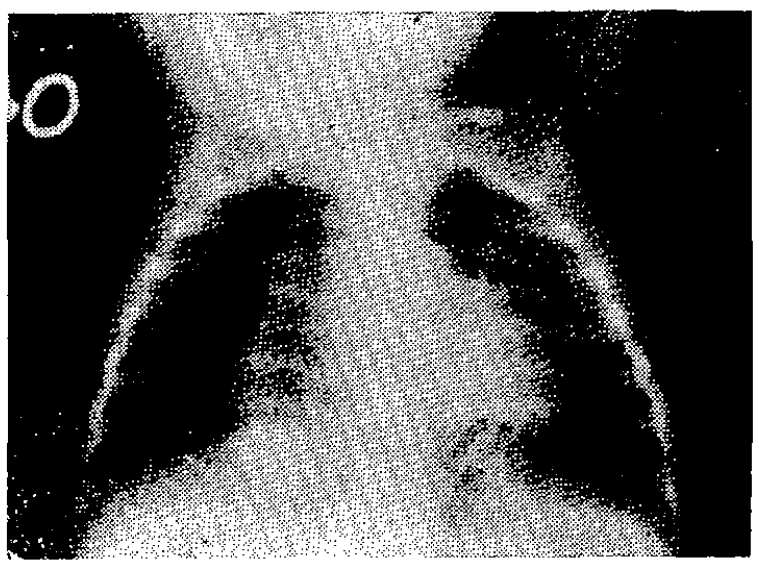

Figura $N^{o}: 4$

A los 12 meses de edad se hospitaliza nuevamente por presentar neumopatía aguda de predominio derecho. Las radiografías demostraron condensación irregular paratraqueal y basal derecha, condensación retrocardíaca izqda. Se practicó punción pulmonar en la que se encontró estafílococos dorado, por lo que se trató con penicilina semisintética, aunque radiológicamente no impresionó como neumopatía supurativa. La evolución radiográfíca presentó sospechosa imagen aérea de aspecto lineal que se extendia hacia diafragma (Fig. 4). Para descartar posibilidad de hernia diafragmática se efectuó enema baritado cl que fue negativo. Como no se aclararan estas características se realizó broncografía bilateral, observándose ramas bronquiales inferiores, derecha e izqda. desplazadas por imagen redondeada situada en la parte central del tórax. Angulo carinal abierto, impresión sobre tercio distal del esófago. Ex. generales de laboratorio n/e. En cirugía se planteó posibilidad de que se tratara de duplicación esofágica.

Histopatológicamente: Quiste bronquial congénito.

\section{COMENTARIO.-}

\section{Etiopatogenia del quiste bronquial congénito}

El tracto respiratorio y digestivo tienen un origen común del intestino primitivo. Posteriormente se produce una invasión por un septum lateral que va a determinar a la larga el esófago y la tráquea. Los quistes broncógenos se forman por una división anormal del árbol traqueobronquial o por un crecimiento anormal del primordio traqueal. Se supone que los quistes intrapulmonares derivan de una división anormal del árbol traqueal, mientras que los quistes carinales y traqueales lo hacen del crecimiento anormal del primordio traqueobrónquico. 
Durante la vida embrionaria se supone que puede haber migración del botón primario lo que explica que se hayan encontrado quistes con caracteres de quistes broncógenos en otras ubicaciones dentro del organismo.

Los botones primarios están revestidos de epitelio secretor y dependiendo si tienen comunicación o no con el árbol bronquial darán imágenes densas o aireadas después del nacimiento (6).

Los quistes broncógenos pueden ser simples o múltiples. Los múltiples generalmente invaden varios segmentos de un lóbulo, pero excepcionalmente lóbulos contiguos. Casi nunca son bilaterales (7).

\section{Anatomía Patológica del quiste bronquial congénito}

Macroscópicamente el quiste es esférico con una muralla fina conteniendo ya sea aire y/o material mucoso denso y oscuro o un material seroso claro.

Cuando es oscuro se atribuye a hemorragia antigua.

Al corte el quiste puede ser trabeculado o multilocular.

Microscópicamente están revestidos por epitelio pseudoestratrificado ciliado (Fig. 5) y en algunos lugares puede haber metaplasia escamosa. Las paredes, del quiste están constituidas por tejido conjuntivo fibroso que comúnmente, pero no siempre, contiene glándulas, cartílago hialino, músculo liso, fibras elásticas, troncos nerviosos, solos o en combinación.

Cuando ha habido infección la estructura se pierde haciéndose el diagnóstico histológico muy difícil y a veces imposible (6). Raramente pueden calcificarse, no se han registrado quistes con evidencias óseas (8).

Clasificación de los quistes bronquiales congénitos. Existen varias clasificaciones, entre otras la de Cooke, F. N. y Blades B. (9), pero parece mejor hacerlo de acuerdo a su ubicación anatómica $(10,11)$ en la siguiente forma:

Traqueales
Hiliares
Carinales
Pulmonares, alveolares
Esofágicos
Misceláneos

Signos y síntomas. Pueden cursar como: 1. Obstrucción traqueobrónquica alta acompañada de dificultad respiratoria. 2. Obs-

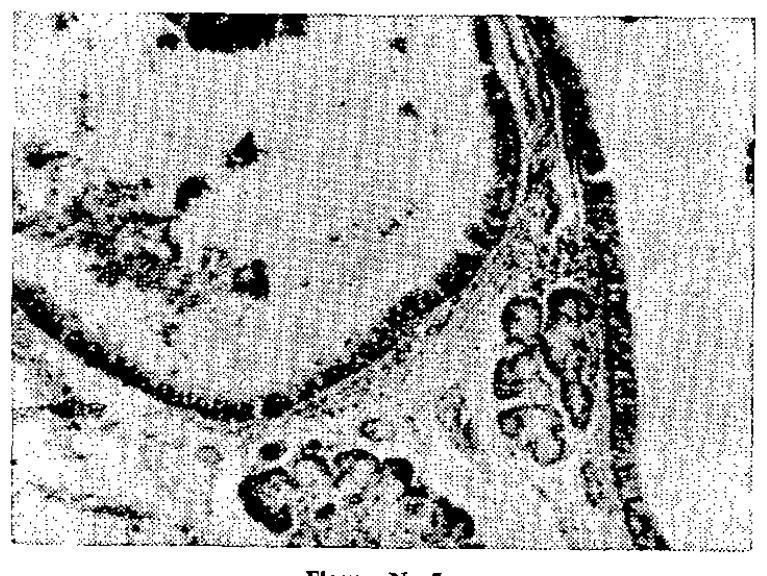

FIgura No 5

Microfotografía. Cavidades contiguas revestidas por epite. lio de tipo bronquial con glándulas subrnucosas. Hematoxilina-eosina. $6,3 \mathrm{X}$.

trucción moderada de la vía aérea con supuración distal. 3. Supuración del quiste por contaminación de su contenido a través de la comunicación con, la luz respiratoria (3-6). 4. Pueden cursar en forma asintomática. Los quistes de la bifurcación son más capaces de producir obstrucción respiratoria durante la lactancia y aun muerte por compresión de la tráquea o de los bronquios principales (12).

La supuración del quiste puede dar lugar a necrosis del epitelio que se ve reemplazado por tejido de granulación con infección crónica. Cualesquiera de estas formas de presentación, pueden acompañarse de insuficiencia respiratoria, manifestaciones severas de infección o de hemoptisis.

Una tos persistente y de timbre metálico puede estar indicando compresión mediastínica por un quiste (13).

Radiología. Los quistes se caracterizan por la aparición de imágenes redondeadas, generalmente no calcificada, perfectamente definida, de tamaño variable, que no se modifica con el tiempo o que lo hace lentamente.

Si se infecta o si las secreciones son retenidas en el interior del mismo se forma un nivel hidroaéreo. Si está lleno de líquido la lesión aparece como una masa sólida. La diferenciación con neumatoceles puede ser difícil, pero en ellos existen antecedentes neumónicos previos. Estos tienen una pared extremadamente delgada y en semanas o meses muestran una reducción gradual y cuando se trata de niños pequeños desaparecen en un gran porcentaje (14). El quiste broncógeno mediastínico suele ser homogéneo y en raras ocasiones comunica con el árbol traqueobronquial. La localización más fre- 
cuente es la subcarinal, los del parénquima se ubican con más frecuencia en los campos pulmonares inferiores $(6,15,16)$. En el trabajo de Rogers y colaboradores (6), que reúne 32 quistes pulmonares, en 18 se efectuó broncografía y en seis hubo llenamiento con medio de contraste. En toda imagen sospechosa de quiste y sobre todo que no se aclare el cuadro con radiografias frontales y laterales, debe efectuarse estudio broncográfico (17).

Diagnóstico diferencial. Junto a la clínica, la radiología desempeña un papel fundamental en el diagnóstico. Las sombras redondeadas mayores son fáciles de demostrar radiológicamente, pero de difícil interpretación. Pueden aparecer en forma aislada o múltiple, estar situadas en pulmón, mediastino o marginales a la pleura. Las causas más frecuentes de sombras redondeadas solitarias son: 1) Pioneumatocele. 2) Quiste hidatídico. 3) Tumores. 4) Tuberculosis. 5) Quistes cerrados pulmonares o broncógenos, infarto pulmonar, 6) Metástasis pulmonares. 7) Hernias diafragmáticas. 8) Secuestros pulmonares. 9) Fístula arteriovenosa pulmonar $(18,19) .10)$ Riñón ectópico.

Discusion. Los quistes broncógenos se forman de una división anormal del árbol traqueobronquial o por crecimiento alterado del primordio traqueal. Se ubican preferentemente en el mediastino, e incluso pueden hacerlo extratorácicamente.

Histopatológicamente, se caracterizan por su epitelio, pseudo-estratificado ciliado. Radiológicamente se presentan como una imagen redondeada, perfectamente definida y que se modifican lentamente en el tiempo. Su tratamiento es exclusivamente quirúrgico.

En el departamento de enfermedades respiratorias del hospital M. Arriarán, entre 5200 egresos en un período de 17 años, 48 casos correspondieron a patología congénita y el $25 \%$ fueron quistes bronquiales congénitos.

El quiste bronquial congénito, puede dificultar el diagnóstico del enfisema lobar congénito (caso C.J.G.).

El hallazgo de signos de hemorragia antigua en material de punción es sugerente de Q.B.C. (Caso J.I.M.).

El estudio radiológico precoz en niños con cuadros respiratorios recidivantes posibilita el diagnóstico en pacientes con Q.B.C. evitando retardos innecesarios. (Caso S.V.H.).

El uso de técnica broncográfica permite el diagnóstico diferencial con neumopatías de otra naturaleza.

La infección crónica o recurrente secundaria puede alterar o destruir de tal manera la arquitectura pulmonar que haga imposible el diagnóstico de la lesión original lo que podría dar lugar a diagnósticos inespecíficos en el adulto.

\section{RESUMEN}

Se presentan cuatro casos de quiste bronquial congénito con caracteres clinicos radiológicas y evolutivos disimiles; no obstante en los cuatro la sintomatología fue precoz.

Se destaca la importancia de la técnica broncográfica que permite el diagnóstico diferencial y que debería ser utilizada precozmente.

\section{SUMMARY}

4 cases of congenital bronchogenic cysts with dissimilar clinical features, radiological findings and evolution are presented.

In all of them symptomatology was precocious.

The importance of bronchographic technique is emphasized in order to permit differential diagnosis and it must be uscd precociously.

\section{REFERENCIAS}

1.- Willich, E. Práctica Pediátrica. 1: 87. 1970.

2.- Crofton J., Douglas A., Enfermedades respiratorias. Marín. Barcelona. 568, 1971.

3.- Kendig E.L., Pulmonary disorders. Saunders, Philadelphia. 1972.

4.- Morrison I.M., Tummours and Cysts of the mediastinum. Thorax; 13, 294, 1958.

5.- Kissane J.M., Smith M.G., Pathology of infancy and childhood St. Louis, 411, 1967.

6.- Rogers LF. y col. Bronchogenic Cyst, A revew of 46 cascs. Am. J. Roentgenol. 91; 273$283,1964$.

7.- Patten B.M., El Ateneo. Bucnos Aires. 1960.

8.- Corwin Hinshaw. Enfermedades del tórax. Interamericana. México. 276, 1970.

9.- Cook F.N. y Blades B.B., Cystic diseases of the lung. J. Thoracic. Surg. 23, 546, 1952. 
10.- Maier R.C. Bronchogenic cyst of the medias. tinum. An. Surg. 127: 476, 1948.

11.- Yyons HA., Calvy G.L. y Sammons B.P., The diagnosis and classification of mediastinal masses. An. intern. Med. 51, 897, 1959.

12.- Rubin E.H. Enfermedades del tórax. Toray. Barcelona. 616, 1965.

13.- Boyd G.L., Solid Intrathoracic masses in children. Pediatrics: 19, 142, 1957.

14.- Burdach R., Varas A., Hasbún J., Pioneumatocele, aspectos clínicos y radiológicos en 25 casos. Rev. Chil. Pediat. 1969.
15.- Caffey J., Diagnóstico radiológico en Pediatría. Salvat. Barcelona. 1970.

16.- Singleton E.B., Wagner M.L., Atlas de anomalías pulmonares en el niño. Pediátrica. Barcelona. 1972.

17.- Cortés E., Guirardi G., Broncografía. Rev. Chil. Pediat. 43: 11-12; 42-44, 1972.

18.- Cocchi U., Thurn P., Roentgendiagnóstico. Marín. Barcelona. 135, 1962.

19.- Hope, J.W. y Koop, C.E., Differential diagnosis of mediastinal Mass. Pediatric Clinic N.A. $6,379,1959$. 